\title{
High faecal carriage of extended-spectrum beta-lactamase producing Enterobacteriaceae (ESBL-PE) among hospitalized patients at Sylvanus Olympio Teaching Hospital, Lomé, Togo in 2019
}

\author{
*1,2 Godonou, A. M., ${ }^{2}$ Lack, F., ${ }^{3,4}$ Gbeasor-Komlanvi, F. A., ${ }^{2}$ Konlani, L., ${ }^{2,3}$ Dos
${ }^{1}$ Ameyapoh, Y. A., ${ }^{3,4}$ Ekouevi, K., ${ }^{2,3}$ Dagnra, A. Y., and ${ }^{3,5}$ Salou, M. \\ ${ }^{1}$ High School of Biological and Food Technics, University of Lomé, Togo \\ ${ }^{2}$ Teaching Hospital Sylvanus Olympio, Lomé, Togo \\ ${ }^{3}$ Faculty of Health Sciences, University of Lomé, Togo \\ ${ }^{4}$ Faculty of Health Sciences Public Heath Department, University of Lomé, Togo \\ ${ }^{5}$ Teaching Hospital Campus, Lomé, Togo \\ *Correspondence to: godonouvirginie@yahoo.fr
}

\begin{abstract}
:
Background: Extended-spectrum beta-lactamase producing Enterobacteriaceae (ESBL-PE) are a global health concern, associated with increased morbidity and mortality. Even in the absence of infections, colonization by these pathogens is still a great threat because of the risk of cross transfer among hospitalized patients. Faecal carriage of ESBL-PE remained poorly documented in Africa. This study aimed to determine faecal carriage rate of ESBL-PE, factors associated with carriage, and antimicrobial susceptibility of the strains among hospitalized patients at Sylvanus Olympio Teaching Hospitals (CHU SO) in Lomé, Togo.

Methodology: This was a cross-sectional study of 105 randomly selected hospitalized patients between September and November 2019. Socio-demographic and clinical data as well as rectal swabs were collected after obtaining the consent of the selected participants. Rectal swabs were cultured on selective bromocresol purple (BCP) lactose agar containing $6 \mu \mathrm{g} / \mathrm{l}$ ceftazidime, for isolation of Enterobacteriaceae. Identification of each isolate was performed using Uriselect 4 medium and API 20E. Antibiotic susceptibility of the bacterial isolates was performed by the Bauer-Kirby agar disc diffusion test and interpreted according to CASFM-EUCAST recommendations.

Results: The faecal carriage rate of ESBL-PE among selected hospitalized patients was 80.9\% (85/105). Escherichia coli was the most frequent bacteria 69.5\% (73/105), followed by Klebsiella pneumoniae $22.8 \%$ (24/105). The antibiotic profile of ESBL producing Escherichia coli showed resistance to amoxycillin+clavulanic acid (72.6\%), ticarcillin+clavulanic acid (82.2\%), piperacillin+tazobactam (30.1\%), cefoxitin (30.1\%) ciprofloxacin (84.9\%), levofloxacin $(76.7 \%)$, nalidixic acid $(83.6 \%)$, chloramphenicol $(26.0 \%)$, gentamicin $(49.3 \%)$, sulfamethoxazole-trimethoprim $(86.3 \%)$, imipenem $(5.5 \%)$, and ertapenem $(21.9 \%)$. All $(100 \%)$ isolates were sensitive to amikacin and fosfomycin. None of the characteristics or risk factors assessed was significantly associated with faecal carriage of ESBL-PE.

Conclusion: Faecal carriage rate of ESBL-PE in these hospitalized patients was very high, but no factor was associated with carriage of ESBL-PE among the study population. Implementation of infection control measures, and surveillance are needed to limit the spread of these resistant pathogens within CHU SO healthcare facilities.
\end{abstract}

Keywords: Faecal carriage; ESBL; Enterobacteriaceae; hospitalized patients; Togo

Received Sept 20, 2021; Revised Nov 25, 2021; Accepted Dec 6, 2021; Published online Jan 18, 2022

Copyright 2022 AJCEM Open Access. This article is licensed and distributed under the terms of the Creative Commons Attrition 4.0 International License $<$ a rel="license" href="http://creativecommons.org/licenses/by/4.0/", which permits unrestricted use, distribution and reproduction in any medium, provided credit is given to the original author(s) and the source. Editor-in-Chief: Prof. S. S. Taiwo

\section{Fort taux de portage fécal d'Entérobactéries productrices de bêta-lactamases à spectre élargi (E-BLSE) chez les patients hospitalisés au CHU Sylvanus Olympio de Lomé, Togo en 2019}

*1,2Godonou, A. M., ${ }^{2}$ Lack, F., 3,4 Gbeasor-Komlanvi, F. A., ${ }^{2}$ Konlani, L., ${ }^{2,3}$ Dossim, S., ${ }^{1}$ Ameyapoh, Y. A., ${ }^{3,4}$ Ekouevi, K., ${ }^{2,3}$ Dagnra, A. Y., and ${ }^{3,5}$ Salou, M. 
${ }^{1}$ Ecole Supérieure des Techniques Biologiques et Alimentaires, Université de Lomé, Togo

${ }^{2}$ Centre Hospitalier Universitaire Sylvanus Olympio, Lomé, Togo

${ }^{3}$ Faculté des Sciences de la Santé, Université de Lomé, Togo

${ }^{4}$ Faculté des Sciences de la Santé (FSS), Département de Santé Publique, Université de Lomé, Togo

${ }^{5}$ Centre Hospitalier Universitaire Campus, Lomé, Togo

*Correspondance a: godonouvirginie@yahoo.fr

\section{Résumé:}

Contexte: Les entérobactéries productrices de bêta-lactamases à spectre élargi (E-BLSE) constituent un problème mondial de santé associé à une morbidité et une mortalité accrue. Même en l'absence d'infections, la colonisation par ces pathogènes reste une grande menace en raison du risque de transfert croisé entre les patients hospitalisés. Le portage fécal d'E-BLSE est peu documenté en Afrique. Cette étude vise à estimer le taux de portage fécal des E-BLSE, à déterminer les facteurs associés à leur portage et la sensibilité aux antibiotiques des souches chez les patients hospitalisés au Centre Hospitalier Universitaire Sylvanus Olympio (CHU SO) de Lomé, Togo.

Méthodologie: Il s'est agi d'une étude transversale portant sur 105 patients hospitalisés sélectionnés au hasard entre Septembre et Novembre 2019. Les données sociodémographiques, cliniques et des prélèvements rectaux par écouvillonnage ont été collectés, après obtention du consentement des participants. Pour l'isolement des entérobactéries, les écouvillonnages rectaux ont été ensemencés sur une gélose sélective (BCP) contenant $6 \mu \mathrm{g} / \mathrm{l}$ de ceftazidime. L'identification de chaque isolat s'est faite en utilisant le milieu Uriselect 4 et la galerie API 20E. L'étude de la sensibilité aux antibiotiques des isolats bactériens a été réalisée par la technique de diffusion des disques en milieu gélosé (Kirby-Bauer) et interprétée selon les recommandations du CASFMEUCAST.

Résultats: Le taux de portage fécal des E-BLSE chez les patients hospitalisés était de 80,9\% (85/105). Escherichia coli a été la bactérie la plus isolée 69,5\% (73/105), suivie de Klebsiella pneumoniae 22,8\% $(24 / 105)$. Les souches d'Escherichia coli productrices de BLSE ont montré une résistance à l'amoxycilline+acide clavulanique à $(72,6 \%)$, ticarcilline+acide clavulanique $(82,2 \%)$, pipéracilline+tazobactam $(30,1 \%)$, céfoxitine $(30,1 \%)$ ciprofloxacine $(84,9 \%)$, lévofloxacine $(76,7 \%)$, acide nalidixique $(83,6 \%)$, chloramphénicol $(26,0 \%)$, gentamicine $(49,3 \%)$, sulfaméthoxazole-triméthoprime $(86,3 \%)$, imipénem $(5,5 \%)$ et ertapénème $(21,9 \%)$. Tous les isolats $(100 \%)$ étaient sensibles à l'amikacine et à la fosfomycine. Nous n'avons pas retrouvé des caractéristiques ou des facteurs de risque associés au portage fécal des E-BLSE.

Conclusion: Le taux de portage fécal des E-BLSE chez ces patients hospitalisés était très élevé, mais aucun facteur n'était associé à leur portage. La mise en œuvre de mesures de contrôle et de prévention des infections et la surveillance sont nécessaires pour limiter la propagation de ces pathogènes résistants au sein du CHU SO voire des établissements de santé.

Mots-clés: Portage fécal; BLSE; Entérobactéries; patients hospitalisés; Togo

\section{Introduction:}

Extended spectrum $\beta$-lactamase producing Enterobacteriaceae (ESBL-PE) are among the most important pathogens causing infections in both the community and hospital settings in recent years $(1,2)$. Even in the absence of infection, colonization with the extended-spectrum $\beta$-lactamase (ESBL) producing bacteria is a strong cause for concern $(3,4)$. Among them, Klebsiella pneumoniae and Escherichia coli represent the most frequently isolated ESBL-PE worldwide but the ESBLs are also identified in several other bacterial species (5).

In the hospital settings, gastrointestinal carriage of ESBL is the main reservoir of these organisms, and is associated with high risk for developing self and cross infections (6). This is a global issue because infections caused by ESBL producing clinical isolates are associated with high mortality, increased length of hospital stays and health care cost, and longer duration of antibiotic therapy, when compared to infections caused by nonESBL producing pathogens (7). Furthermore, ESBL-PE pose significant therapeutic challenge in daily management of infectious diseases due to their resistance to additional classes of antibiotics, thereby reducing the effectiveness of alternative antimicrobial regimens $(8,9)$. The co-existence of multiple ESBLs in the same clinical strain including AmpC beta-lactamases, carbapenemases and other antibiotic resistance plasmid determinants further creates therapeutic challenges (10).

Faecal carriage of ESBL-PE has been increasingly reported worldwide over the last decade, with the highest ESBL-PE carriage rates being reported in Asia (11), while carriage rates are lower in Europe and North America $(12,13)$. Some studies in Africa have investigated and reported faecal carriage rates of ESBL-PE in the community and in hospitalized patients in Chad, Mauritania, Cameroon, Ethiopia, and Burkina Faso (1418).

In Togo, some researchers have described the phenomenon of bacterial resistance due to ESBLs in the hospital environment from laboratory stains but carriage of ESBL among patients have not been investigated $(19,20)$. The objectives of this study therefore, are to investigate faecal carriage of ESBL-PE among hospitalized patients, determine factors associated with their carriage, and perform antimicrobial suscepti- 
bility on isolated ESBL-PE strains in Sylvanus Olympio Teaching Hospital in Lomé, Togo.

\section{Materials and method:}

\section{Study area}

The Sylvanus Olympio Teaching Hospital (CHU SO) is located in Gulf 4 municipality of big Lome autonomous district (1.5 million inhabitants). It is a national benchmark establishment, with a capacity of 1,138 beds. $\mathrm{CHU} \mathrm{SO}$ is the largest University affiliated teaching hospital in Togo, where patients from different parts of the country are referred for further management. The various technical wards are functionally and administratively organized into seven departments; medicine and medical specialties, surgery and surgical specialties, paediatrics, gynaecoobstetrics, laboratories, medical imaging, preventive medicine and public health. The samples were analysed at the bacteriology laboratory of the hospital.

\section{Study design and participants}

This was a cross-sectional study conducted from September to November 2019 on 105 randomly selected volunteer hospitalized patients after obtaining their consent to participate in the study. Inclusion criteria for study participants were all hospitalized patients including children and adult patients who have been admitted for $\geq 48$ hours, and who consented to participate in the study. Participants were selected from eight hospitalization wards; military flag, medicine, neurology, polyvalent reanimation, gynaecology and obstetrics, traumatology, visceral surgical, and paediatrics.

\section{Ethical approval}

Ethical approval for the study was obtained from the Scientific and Ethical Committee of the Health Research Ethics Committee (048/2019/CBRS) of Health Ministry of Togo. Written informed consent of each adult participant and from parent or guardian of children were obtained. The confidentiality of data obtained was assured.

\section{Data and sample collection}

Socio-demographic data and risk factors were collected from patients using a selfadministered questionnaire. The socio-demographic information collected included age, gender, place of residence, and education level, while information on risk factors for carriage of ESBL included length of hospitalization, hospitalization in the previous year, and antimicrobial use in the previous three months before the study. Rectal sample was collected from each participant using a cotton swab, and transported to the laboratory within 30 minutes of collection.

\section{Bacteriological analysis}

Briefly, each rectal swab was placed in an enrichment broth (thioglycolate broth) and incubated for 5 hours at $37^{\circ} \mathrm{C}$. A loop-full culture from enrichment broth was streaked onto selective BCP lactose agar containing 6 $\mu \mathrm{g} / \mathrm{l}$ cefotaxime, and incubated aerobically at $37^{\circ} \mathrm{C}$ for $18-24$ hours.

ESBL-producing strains of Enterobacteriaceae which grow on selective BCP agar were selected according to their morphological appearance and re-isolated on Uriselect 4 medium for identification while non-ESBLproducing strains will not grow on this selective medium. Escherichia coli appeared pink in colour on Uriselect medium. Other isolates were identified to species level using commercial API 20E gallery (BioMérieux, France).

\section{Antimicrobial susceptibility testing (AST)}

Antimicrobial susceptibility testing of Enterobacteriaceae isolates was performed using the Kirby Bauer disk diffusion method on Mueller Hinton agar following standard zone size interpretative criteria recommended by the 2019 CASFM-EUCAST (European Committee of Antibiotic Susceptibility Testing) (21). Four identical colonies from overnight culture on Mueller-Hinton (MH) medium was picked using sterile Pasteur loop and emulsified in $5 \mathrm{ml}$ of sterile normal saline and the inoculum density was adjusted to equal that of 0.5 McFarland turbidity standards ( $1.5 \mathrm{x}$ $10^{8} \mathrm{CFU} / \mathrm{ml}$ ). Using a sterile swab, the inoculum was spread on Mueller Hinton agar and allowed to dry. Antimicrobial discs (Oxoid, UK) were placed on the medium $30 \mathrm{~mm}$ apart and $15 \mathrm{~mm}$ away from the edge of the plate, and incubated at $37^{\circ} \mathrm{C}$ for 24 hours to obtain a lawn culture growth. The inhibition zone diameter (in $\mathrm{mm}$ ) was measured with a calibrated ruler and interpreted according to the recommendations of 2019 EUCAST (21).

The isolates were tested against a panel of 21 antimicrobials in different classes that are commonly used to treat human bacterial infections, and includes; ampicillin $10 \mu \mathrm{g}$, ticarcillin $75 \mu \mathrm{g}$, amoxicillin+clavulanic acid 30 $\mu \mathrm{g}$, ticarcillin+clavulanic acid $85 \mu \mathrm{g}$, cefoxitin $30 \mu \mathrm{g}$, piperacillin $30 \mu \mathrm{g}$, piperacillin+tazobactam $36 \mu \mathrm{g}$, ceftazidime $10 \mu \mathrm{g}$, ceftriaxone 30 $\mu \mathrm{g}$, aztreonam $30 \mu \mathrm{g}$, cefepime $30 \mu \mathrm{g}$, imipenem $10 \mu \mathrm{g}$, ertapenem $10 \mu \mathrm{g}$, amikacin $15 \mu \mathrm{g}$, gentamicin $10 \mu \mathrm{g}$, chloramphenicol 30 $\mu \mathrm{g}$, sulfamethoxazole-trimethoprim $25 \mu \mathrm{g}$, nalidixic acid $30 \mu \mathrm{g}$, ciprofloxacin $5 \mu \mathrm{g}$, levofloxacin 5 $\mu \mathrm{g}$, and fosfomycin $200 \mu \mathrm{g}$. A standard reference strain of Escherichia coli ATCC25922 (which is sensitive to all the tested antimicrobial agents) was used as control strain.

\section{Detection of ESBL by double disk method}

All isolated strains of Enterobacteriaceae were tested for ESBL production by the 
double disk method (21). Combination disks of amoxicillin+clavulanic acid $(20+10 \mu \mathrm{g})$ or ticarcillin+clavulanic acid $(75+10 \mu \mathrm{g})$ was applied to the center of Mueller-Hinton agar that has been inoculated with the test strain. Ceftazidime $(10 \mu \mathrm{g})$ and cefepime $(30 \mu \mathrm{g})$ disks frame the ticarcillin+clavulanic acid disk $30 \mathrm{~mm}$ apart from each other and $15 \mathrm{~mm}$ from the edge of the plate. After 18-24 hours of incubation at $37^{\circ} \mathrm{C}$, isolate that showed increase of $\geq 5 \mathrm{~mm}$ in the zone of inhibition of the combination disks in comparison to that of the ceftazidime and cefepime disk was considered an ESBL. Escherichia coli ATCC 25922 and Klebsiella pneumoniae ATCC 700603 were used as negative and positive control strains, respectively.

\section{Statistical analysis of data}

Data were entered into Excel software. Statistical analysis was performed using SPSS software (IBM SPSS Statistics 21, Armonk, NY). Chi-square test at 5\% level of significance was used to assess the prevalence differences. Multivariate logistic regression analyses were performed to investigate the risk factors associated with ESBL-PE carriage including calculation of the Odd ratio (OR) and 95\% Confidence Interval (CI). A threshold of $p$ value $<0.05$ was considered significant for multivariate analyses, and also if $O R$ is $>1$ and value of 1 is not included in the CI range.

\section{Results:}

Socio-demographic and clinical characteristics of study participants

Of the total of 105 participants, 46 $(43.8 \%)$ were males while $59(56.2 \%)$ were females. The age of the participants ranged from 1 month to 80 years with a median age of 40 years. A total of $49(46.7 \%)$ participants had secondary school education, 65 $(61.9 \%)$ had been hospitalized for more than 7 days, 14 (13.3\%) had been hospitalized in the year preceding current hospitalization, and $47(44.8 \%)$ had used antibiotics within 3 months preceding hospitalization (Table 1 ).

Carriage rate of Enterobacteriaceae isolates Escherichia coli $(69.5 \%, \mathrm{n}=73)$, followed by $K$. pneumoniae $(22.9 \%, n=24)$ and Enterobacter cloacae $(3.8 \%, \mathrm{n}=4)$ were the most frequently isolated Enterobacteriaceae from the rectal specimens (Fig. 1). The carriage rate of ESBL-producing Enterobacteriaceae was $80.9 \%(n=85)$ of the 105 hospitalized patients while $19.1 \% \quad(n=20)$ were carrier of non-ESBL-producing Enterobacteriaceae. In 19 (22.4\%) patients who carried ESBL-PE, association of two strains (21.2\%) and three ESBL bacteria was found, with $E$. coli and $K$. pneumoniae association being the most frequent (Table 2 ).

\section{Carriage rate of ESBL-PE according to the hospitalization department}

The carriage rate of ESBL-PE by ward in the hospital is shown in Table 3. Carriage rates were highest among patients in polyvalent intensive care unit (100\%) and in the traumatology and medicine wards, with over $90 \%$ ESBL-PE carriage rate each.

\section{Factors associated with carriage of ESBL-PE}

Statistical analysis in Table 1 showed that no socio-demographic characteristic (gender, age group, educational level) or risk factor (length of hospitalization, previous hospitalization, use of antibiotics in preceding 3 months), was significantly associated with carriage of ESBL-PE in the study population ( $p>0.05$ for all analyses).

\section{Resistance profiles of isolates}

The antimicrobial resistance profile of ESBL-producing E. coli, K. pneumoniae, and E. cloacae showed that they were $100 \%$ resistant to ampicillin, ticarcillin, piperacillin, ceftazidime, ceftriaxone, aztreonam and cefepime. Escherichia coli isolates showed high resistance of over $70 \%$ to amoxycillin+clavulanic acid $(72.6 \%)$, ticarcillin+clavulanic acid $(82.2 \%)$, sulfamethoxazole - trimethoprim $(86.3 \%)$, nalidixic acid $(83.6 \%)$, ciprofloxacin $(84.9 \%)$ and levofloxacin $(76.7 \%)$. However, resistance rate of $E$. coli isolates was less than $50 \%$ to piperacillin+tazobactam $(30.1 \%)$ cefoxitin $(30.1 \%)$, chloramphenicol $(26.0 \%)$, gentamicin $(49.3 \%)$, imipenem $(5.5 \%)$, and ertapenem $(21.9 \%)$. Klebsiella pneumoniae isolates showed high resistance of over $50 \%$ to piperacillin+tazobactam (66.7\%), ciprofloxacin $(91.7 \%)$, levofloxacin $(79.2 \%)$, nalidixic acid (54.2\%), chloramphenicol (54.2\%), gentamicin $(95.8 \%)$, and sulfamethoxazoletrimethoprim $(88.9 \%)$, but low resistance to cefoxitin $(20.8 \%)$, However, both $E$. coli and K. pneumoniae isolates were $100 \%$ sensitive to amikacin and fosfomycin (Table 4). 
Table 1: Socio-demographic and clinical characteristics of participants with respect to carriage of Enterobacteriaceae

\begin{tabular}{|c|c|c|c|c|c|}
\hline Characteristics & $\begin{array}{c}\text { ESBL carriers } \\
\text { n }(\%)\end{array}$ & $\begin{array}{c}\text { Non-ESBL carriers } \\
\text { n ( } \%)\end{array}$ & $p$ value & $X^{2}$ & $\begin{array}{c}\text { OR } \\
(95 \% \mathrm{CI})\end{array}$ \\
\hline \multicolumn{6}{|l|}{ Age group (years) } \\
\hline$<20$ & $21(25.0)$ & $3(15.0)$ & 0.6437 & 3.366 & NA \\
\hline $20-29$ & $11(13.0)$ & $3(15.0)$ & & & \\
\hline $30-39$ & $11(13.0)$ & $1(5.0)$ & & & \\
\hline $40-49$ & $13(15.0)$ & $5(25.0)$ & & & \\
\hline $50-59$ & $10(12.0)$ & $4(20.0)$ & & & \\
\hline$\geq 60$ & $19(22.0)$ & $4(20.0)$ & & & \\
\hline \multicolumn{6}{|l|}{ Gender } \\
\hline $\begin{array}{l}\text { Female } \\
\text { Male }\end{array}$ & $\begin{array}{l}47(55.0) \\
38(45.0)\end{array}$ & $\begin{array}{l}12(60.0) \\
8(40.0)\end{array}$ & 0.8956 & 0.01721 & $\begin{array}{c}0.8246 \\
(0.3058-2.223)\end{array}$ \\
\hline \multicolumn{6}{|l|}{ Education level } \\
\hline $\begin{array}{l}\text { Less than Secondary } \\
\text { Secondary and above }\end{array}$ & $\begin{array}{l}44(52.0) \\
41(48.0)\end{array}$ & $\begin{array}{l}12(60.0) \\
8(40.0)\end{array}$ & 0.6780 & 0.1723 & $\begin{array}{c}0.7154 \\
(0.2656-1.927)\end{array}$ \\
\hline \multicolumn{6}{|c|}{ Length of hospitalization } \\
\hline $\begin{array}{l}\leq 7 \text { days } \\
>7 \text { days }\end{array}$ & $\begin{array}{l}29(34.0) \\
56(66.0)\end{array}$ & $\begin{array}{l}11(55.0) \\
9(45.0)\end{array}$ & 0.1404 & 2.174 & $\begin{array}{c}0.4237 \\
(0.1576-1.139)\end{array}$ \\
\hline \multicolumn{6}{|c|}{ Previous hospitalization in preceeding year } \\
\hline $\begin{array}{l}\text { No } \\
\text { Yes }\end{array}$ & $\begin{array}{l}75(88.0) \\
10(12.0)\end{array}$ & $\begin{array}{l}16(80.0) \\
4(20.0)\end{array}$ & 0.5424 & 0.3712 & $\begin{array}{c}1.875 \\
(0.5217-6.739)\end{array}$ \\
\hline \multicolumn{6}{|c|}{ Antimicrobial use in the previous 3 months } \\
\hline $\begin{array}{l}\text { No } \\
\text { Yes }\end{array}$ & $\begin{array}{l}45(53.0) \\
40(47.0)\end{array}$ & $\begin{array}{l}13(65.0) \\
7(35.0)\end{array}$ & 0.4679 & 0.5269 & $\begin{array}{c}0.6058 \\
(0.2200-1.668)\end{array}$ \\
\hline
\end{tabular}

$X^{2}=$ Chi square; OR=Odds Ratio; NA=Not Applicable; $\mathrm{n}=$ no of participants; CI=Confidence Interval; ESBL=Extended Spectrum Beta Lactamase

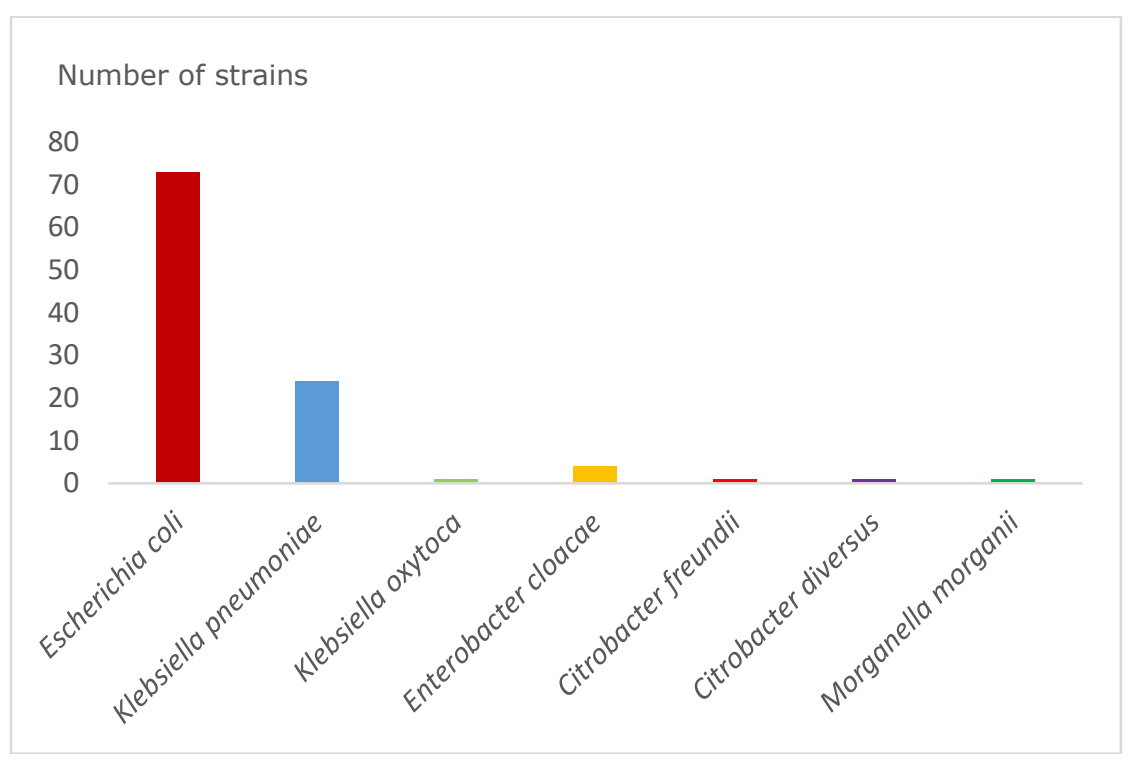

Fig 1 : Frequency distribution of Enterobacteriaceae isolates among hospitalized patients at Sylvanus Olympio Teaching Hospital in Lomé, 2019 
Table 2: Multiple Enterobacteriaceae isolates in hospitalized patients at Sylvanus Olympio Teaching Hospital, Lomé, 2019

\begin{tabular}{lcc}
\hline Bacteria & N & Percentage \\
\hline Escherichia coli, Klebsiella pneumoniae & 10 & 11.8 \\
Escherichia coli, Escherichia coli & 3 & 3.5 \\
Escherichia coli, Enterobacter cloacae & 1 & 1.2 \\
Escherichia coli, Morganella morganii & 1 & 1.2 \\
Escherichia coli, Citrobacter diversus & 1 & 1.2 \\
Klebsiella pneumoniae, Enterobacter cloacae & 1 & 1.2 \\
Klebsiella pneumoniae, Citrobacter freundii & 1 & 1.2 \\
Escherichia coli, Klebsiella pneumoniae, & 1 & 1.2 \\
Enterobacter cloacae & & \\
\hline
\end{tabular}

$\mathrm{N}=$ no of hospitalized patients

Table 3: Distribution of ESBL-PE carriage rate in hospitalized patients at Sylvanus Olympio Teaching Hospital in 2019

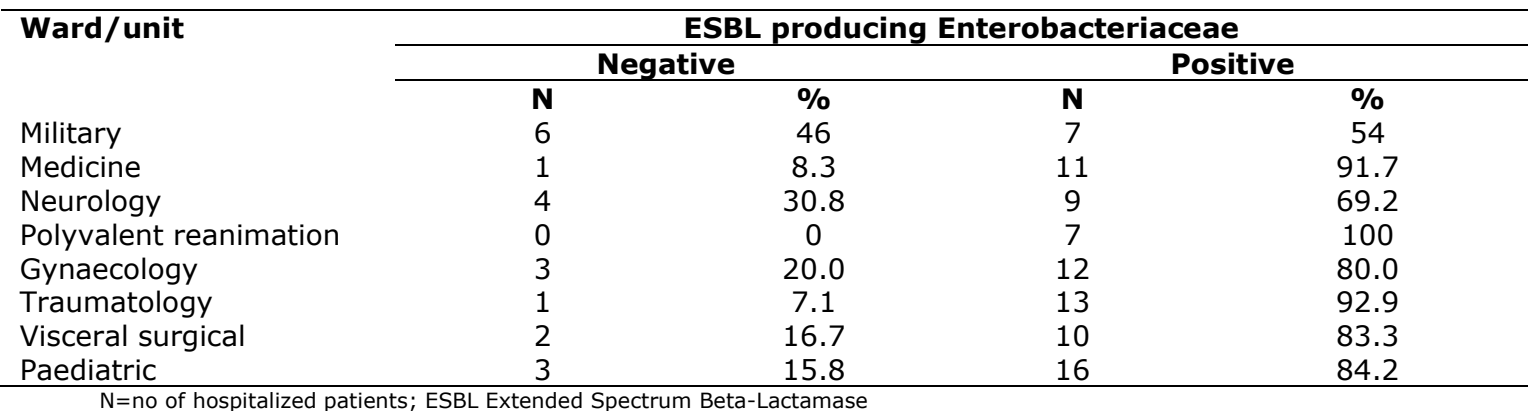

\section{Discussion:}

Colonisation with ESBL-PE is a risk factor for ESBL-PE infections, which are associated with difficulty in initiating effective treatment, prolonged hospitalization, increased healthcare costs, morbidity and mortality (22). Our study recorded high faecal carriage rate $(80.9 \% \%)$ of ESBL-PE in hospitalized patients in Lomé, Togo, which agrees with reports of high intestinal carriage of ESBL-PE in sub-Saharan Africa countries such as Burkina Faso (70\%), Chad (51\%), and Tanzania (59.7\%) (14,18,23,24). Desta et al., (17) in Ethiopia and Kurz (15) in Rwanda also reported high colonisation rates of $52 \%$ and $50 \%$ respectively in their studies. The findings of our study and those of others could be explained by high antibiotic consumption that favors selection of antibiotic resistant bacteria (ARB) and/or high rate of inhospital acquisition of ARB that then colonize the patient's intestinal tract $(26,27)$. Several factors can contribute to high ARB selection in low-income countries, particularly from poor drug quality or inadequate posology, long treatment, increase antimicrobial use by healthcare professionals, unskilled practitioners, auto-medication (because antibiotics can be purchased without prescription), poor hygiene, resulting in the spread of resistant bacteria, and inadequate surveillance programs (28-30).

Escherichia coli was the most frequently isolated ESBL-PE with $69.5 \%$ followed by $K$. pneumoniae $22.9 \%$, which is similar to the findings from a study conducted in Chad (14) which reported ESBL-producing $E$. coli of $69 \%$ and $K$. pneumoniae of $21 \%$, and another study by Desta et al., (17) in Ethiopia, which reported $68 \%$ for $E$. coli and $32 \%$ for K. pneumoniae. Our attempt at investigating factors associated with faecal carriage of ESBL-PE among the subjects revealed that none of the characteristics or risk factors assessed was significantly associated with carriage. This finding differs from those of previous studies conducted in France (31) in which length of hospitalization and high antimicrobial consumption were identified risk factors, and that of Rubio-Perez in Spain (26) who also reported that previous hospitalization and antibiotic treatment were risk factors associated with faecal carriage of ESBL-PE among their patients.

In our study, most ESBL-PE isolates were resistant to three or more classes of antimicrobials, which included mainly quinolones, aminoglycosides (except amikacin), and co-trimoxazole (trimethoprim-sulfamethoxazole). We noticed high resistance rates of $E$. coli isolates to sulfamethoxazole-trimethoprim, nalidixic acid and fluoroquinolones but low resistance rates to chloramphenicol (26.0\%) and complete susceptibility (100\%) to amikacin and fosfomycin. Cross-resistance of ESBLs to other drug classes such as aminoglycosides and fluoroquinolones has been previously documented $(32,33)$. Findings from our study corroborated the Ethiopia study (17), which reported high co-resistance pattern to the to the antibiotic classes in all 


\begin{tabular}{|c|c|c|c|c|}
\hline \multirow[t]{2}{*}{ Antimicrobial class } & \multirow[t]{2}{*}{ Antimicrobial disk } & \multicolumn{3}{|c|}{ Percentage of isolates resistant } \\
\hline & & $\begin{array}{c}\text { Escherichia } \\
\text { coli } \\
(n=73)\end{array}$ & $\begin{array}{c}\text { Klebsiella } \\
\text { pneumoniae } \\
(n=24)\end{array}$ & $\begin{array}{c}\text { Enterobacter } \\
\text { cloacae } \\
(n=4)\end{array}$ \\
\hline \multirow[t]{13}{*}{ Beta - lactams } & Ampicillin $(10 \mu \mathrm{g})$ & 100 & 100 & 100 \\
\hline & Amoxicillin-Clavulanic acid $(20-10 \mu \mathrm{g})$ & 72.6 & 0 & 100 \\
\hline & Ticarcillin $(75 \mu \mathrm{g})$ & 100 & 100 & 100 \\
\hline & Ticarcillin-Clavulanic acid $(75-10 \mu \mathrm{g})$ & 82.2 & 0 & 100 \\
\hline & Piperacillin $(30 \mu \mathrm{g})$ & 100 & 100 & 100 \\
\hline & Piperacillin-Tazobactam $(36 \mu g)$ & 30.1 & 66.7 & 75 \\
\hline & Cefoxitin $(30 \mu \mathrm{g})$ & 30.1 & 20.8 & 75 \\
\hline & Ceftazidime $(10 \mu \mathrm{g})$ & 100 & 100 & 100 \\
\hline & Ceftriaxone $(30 \mu \mathrm{g})$ & 100 & 100 & 100 \\
\hline & Cefepime $(30 \mu \mathrm{g})$ & 100 & 100 & 100 \\
\hline & Aztreonam $(30 \mu \mathrm{g})$ & 100 & 100 & 100 \\
\hline & Imipenem $(10 \mu \mathrm{g})$ & 5.5 & 8.3 & 25 \\
\hline & Ertapenem $(10 \mu \mathrm{g})$ & 21.9 & 29.2 & 50 \\
\hline \multirow[t]{2}{*}{ Aminoglycosides } & Amikacin $(30 \mu \mathrm{g})$ & 0 & 0 & 0 \\
\hline & Gentamicin $(10 \mu \mathrm{g})$ & 49.3 & 95.8 & 100 \\
\hline $\begin{array}{l}\text { Sulfonamides and } \\
\text { associates }\end{array}$ & $\begin{array}{l}\text { Sulfamethoxazole-Trimethoprim } \\
\qquad(27.75 / 1.25 \mu \mathrm{g})\end{array}$ & 86.3 & 100 & 100 \\
\hline Phenicols & Chloramphenicol $(30 \mu \mathrm{g})$ & 26.0 & 54.2 & 75 \\
\hline \multirow{3}{*}{$\begin{array}{l}\text { Quinolones and } \\
\text { Fluoroquinolones }\end{array}$} & Nalidixic Acid $(30 \mu \mathrm{g})$ & 83.6 & 54.2 & 25 \\
\hline & Ciprofloxacin $(5 \mu \mathrm{g})$ & 84.9 & 91.7 & 50 \\
\hline & Levofloxacin $(5 \mu g)$ & 76.7 & 79.2 & 25 \\
\hline Other family & Fosfomycin $(200 \mu \mathrm{g})$ & 0 & 0 & 25 \\
\hline
\end{tabular}

tested isolates.

We also noticed resistance to carbapenems; imipenem (5.5\%) and ertapenem $(21.9 \%)$. Desta et al., (17) in Ethiopia similarly reported resistance to carbapenem in their study. Resistance to carbapenems can be explained by the increased use of this newer generation antimicrobials for the treatment of ABR infections caused by ESBL-PE in hospitals in the event of a therapeutic impasse. Treatment of severe infections caused by ESBL producing $E$. coli and K. pneumoniae in hospitalized patients rely on carbapenems, which are the last resort antibiotics reserved for treatment of life-threatening infections. Infections caused by carbapenemase-producing Enterobacteriaceae (CPE) are most difficult to manage and are associated with high mortality rates (34).

Patients colonized with ESBL are at increased risk for invasive infections compared with non-colonized patients (35). If hand hygiene is not applied as recommended, these resistant bacteria can spread from one patient to another through contaminated hands of healthcare workers. In the hospital setting, identification of patients colonized or infected with ESBL and adoption of preven- 
tive measures such as hand hygiene, and isolation in a single-patient room, is important to prevent cross-transmission and reduce morbidity and healthcare costs (36). Result from our study provides a baseline data necessary to conduct larger studies involving molecular characterization of resistant strains to identify the source, types and the pattern of spread of antimicrobial resistance in Sylvanus Olympio Teaching Hospital.

\section{Conclusion:}

This study revealed high faecal carriage rate of ESBL-PE among hospitalized patients in Sylvanus Olympio Teaching Hospital, Lome, Togo, especially among those admitted into polyvalent reanimation unit. None of the characteristics or risk factors assessed was significantly associated with faecal carriage of ESBL-PE. Routine infection prevention strategies such as rational use of antimicrobial agents, compliance with hand hygiene practices and surveillance of antimicrobial resistance (AMR) are urgently needed to prevent and control the spread of AMR pathogens in healthcare facilities.

\section{Acknowledgements:}

We acknowledge the Director of Sylvanus Olympio Hospital, the heads of hospital departments and supervisors, for their assistance during the conduct of the study. We appreciate with thanks, the head of the laboratory.

\section{References:}

1. Pitout, J. D., and Laupland, K. B, "Extendedspectrum $\beta$ - lactamase-producing Enterobacteriaceae: an emerging public health concern. Lancet Infect Dis. 2008; 8 (3): 159-166.

2. Doi, Y., Park, Y. S., Rivera, J. I., et al. Community-associated extended-spectrum betalactamase-producing Escherichia coli infection in the United States. Clin Infect Dis. 2013; 56 (5): 641-648.

3. Isendahl, J., Turlej-Rogacka, A., Manjuba, C., et al. Fecal Carriage of ESBL-Producing E. coli and K. pneumoniae in Children in Guinea-Bissau: A Hospital-Based Cross-Sectional Study. PLoS One. 2012; 7 (12): e51981.

4. Schwaber, M. J., Lev, B., Israeli, A., et al. Containment of a country-wide outbreak of Carbapenem-resistant Klebsiella pneumoniae in Israeli hospitals via a nationally implemented intervention. Clin Infect Dis. 2011; 52 (7): 848855.

5. Brolund, A. Overview of ESBL-producing Enterobacteriaceae from a Nordic perspective. Infect Ecol Epidemiol. 2014; 4: 1-9.

6. Andriatahina, T., Randrianirina, F., Hariniana, E. R., et al. High prevalence of fecal carriage of extended-spectrum beta-lactamase-producing Escherichia coli and Klebsiella pneumoniae in a pediatric unit in Madagascar. BMC Infect Dis. 2010; 10: 204.
7. Schwaber, M. J. and Carmeli, Y., Mortality and delay in effective therapy associated with extended-spectrum $\beta$-lactamase production in Enterobacteriaceae bacteraemia: a systematic review and meta-analysis. J Antimicrob Chemother. 2007; 60 (5): 913-920.

8. Karisik, E., Ellington, M. J., Pike, R., Warren, R. E., Livermore, D. M., and Woodford, N. Molecular characterization of plasmids encoding CTX-M-15 $\beta$-lactamases from Escherichia coli strains in the United Kingdom. J Antimicrob Chemother. 2006; 58 (3): 665-668.

9. Livermore, D. M. Current epidemiology and growing resistance of Gram-negative pathogens. Korean J Intern Med. 2012; 27 (2): 128-142.

10. Rupp, M. E., and Fey, P. D. Extended spectrum beta-lactamase (ESBL)-producing Enterobacteriaceae: considerations for diagnosis, prevention and drug treatment. Drugs. 2003; 63 (4): 353365.

11. Hawkey, P. M. Multidrug-resistant Gramnegative bacteria: a product of globalization. J Hosp Infect. 2015; 89 (4): 241-247.

12. Pilmis, B., Cattoir, V., Lecointe, D., Limelette, A., et al. Carriage of ESBL-producing Enterobacteriaceae in French hospitals: the PORTABLSE study. J Hosp Infect. 2018; 98 (3): 247-252.

13. Islam, S., Selvarangan, R., Kanwar, N., et al. Intestinal Carriage of Third-Generation Cephalosporin-Resistant and ExtendedSpectrum Beta-Lactamase-Producing Enterobacteriaceae in Healthy US Children. J Pediatr Infect Dis Soc. 2018; 7 (3): 234-240.

14. Mahamat, O. O., Tidjani, A., Lounnas, M., et al. Fecal carriage of extended-spectrum betalactamase producing Enterobacteriaceae in hospital and community settings in Chad. Antimicrob Resist Infect Contr. 2019; 169 (8).

15. Sallem, R. B., Slama, K. B., Estepa, V., et al. Detection of CTX-M-15-producing Escherichia coli isolates of lineages ST410-A, ST617-A and ST354-D in fecal samples of hospitalized patients in a Mauritanian hospital. J Chemother. 2015; 27 (2): 114-116.

16. Djuikoue, I. C., Woerther, P-L., Toukam, M., et al. Intestinal carriage of Extended Spectrum Beta-Lactamase producing $\mathrm{E}$. coli in women with urinary tract infections, Cameroon. J Infect Dev Ctries. 2016; 10 (10): 1135-1139.

17. Desta, K., Woldeamanuel, Y., Azazh, A., et al. High Gastrointestinal Colonization Rate with Extended-Spectrum $\quad \beta$-Lactamase-Producing Enterobacteriaceae in Hospitalized Patients: Emergence of Carbapenemase-Producing $K$. pneumoniae in Ethiopia. PLoS One. 2016; 11 (8): 16.

18. Ouédraogo, A-S., Sanou, S., Kissou, A., et al. Fecal Carriage of Enterobacteriaceae Producing Extended-Spectrum Beta- Lactamases in Hospitalized Patients and Healthy Community Volunteers in Burkina Faso. Microb Drug Resist. 2016; 23 (1): 63-70.

19. Toudji, A. G., Djeri, B., Karou, S. D., Tigossou, S., Ameyapoh, Y., and de Souza, C. Prévalence des souches d'entérobactéries productrices de bêta-lactamases à spectre élargi isolées au Togo et de leur sensibilité aux antibiotiques. Int J Biol Chem. 2017; 11 (3): 1165-1177

20. Salou, M., Assimadi, K., Wateba, I. M., et al. Résistance aux antibiotiques des bactéries isolées en 2009 au laboratoire de bactériologie du CHU-Tokoin Lomé-Togo. J Recher Scient UL. 2011; 13: 151-159.

21. Carter, M. W., Oakton, K. J., Warner, M., and Livermore, D. M. Detection of extendedspectrum beta-lactamases in Klebsiellae with the Oxoid combination disk method. J Clin Microbiol. 2000; 38: 4228-4232.

22. Schwaber, M. J., Navon-Venezia, S., Kaye, K. S., et al. Clinical and economic impact of bacter- 
emia with extended-spectrum-b-lactamase-producing Enterobacteriaceae. Antimicrob Agents Chemother. 2006; 50: 1257-1262.

23. Lonchel, M. C., Melin, P., Gangoué-Piéboji, J., et al. Prevalence and spread of extended-spectrum $\beta$-lactamase producing Enterobacteriaceae in Ngaoundere. Cameroon. Clin Microbiol Infect. 2013; 19 (9): E416-420.

24. Kibwana, U. O., Majigo, M., Kamori, D. and Manyahi, J. High fecal carriage of extended Beta Lactamase producing Enterobacteriaceae among adult patients admitted in referral hospitals in Dar es Salaam, Tanzania. BMC Infect Dis. 2020; 20: 557

25. Kurz, M. S. E., Bayingana, C., Ndoli, J. M., et al. Intense pre-admission carriage and further acquisition of ESBL-producing Enterobacteriaceae among patients and their caregivers in a tertiary hospital in Rwanda. Trop Med Int HIth 2017; 22 (2): 210-220.

26. Rubio-Perez, I. , Martin-Perez, E., Garcia, D. D., Calvo, M. L., and Barrera, E. L. Extendedspectrum beta-lactamase-producing bacteria in a tertiary care hospital in Madrid: epidemiology, risk factors and antimicrobial susceptibility patterns. Emerg HIth Threats J. 2012; 5. doi: 10.3402/ehtj.v5i0.11589.

27. Xu, M., Fan, Y., Wang, M., and Lu, $X$. Characteristics of Extended-Spectrum $\beta$ Lactamases-Producing Escherichia coli in Fecal Samples of Inpatients of Beijing Tongren Hospital. Jpn J Infect Dis. 2017; 70 (3): 290294.

28. Ouedraogo, A. S., Jean Pierre, H., Bañuls, A. L. Ouédraogo, R., and Godreuil, S. Emergence and spread of antibiotic resistance in West Africa: contributing factors and threat assessment. Med Sante Trop. 2017; 27 (2): 147-154.

29. Saravanan, M., Ramachandran, B., and Barabadi, $H$. The prevalence and drug resistance pattern of extended spectrum $\beta$-lactamases
(ESBLs) producing Enterobacteriaceae in Africa. Microb Pathog. 2018; 114: 180-192.

30. Lonchel, C. M., Meex, C., Gangoué-Piéboji, J., et al. Proportion of extended-spectrum Blactamase-producing Enterobacteriaceae in community setting in Ngaoundere, Cameroon. BMC Infect Dis. 2012; 12 (1): 53.

31. Soullie, B., Soler C., Hance, P., et al. Enquête de prévalence sur le portage de bactéries multirésistantes à l'institution nationale des invalides, BHE. 2000 : 16

32. Marbou, W. J. T., and Kuete, V. Bacterial resistance and immunological profiles in HIVinfected and non-infected patients at Mbouda AD LUCEM Hospital in Cameroon. J Infect Publ HIth. 2017; 10 (3): 269-276.

33. Schaumburg, F., Alabi, A., Kokou, C., et al. High burden of extended-spectrum -lactamaseproducing Enterobacteriaceae in Gabon. J Antimicrob Chemother. 2013; 68 (9): 21402143.

34. Ducomble, T., Faucheux, S., Helbig, U., et al. Large hospital outbreak of KPC-2-producing Klebsiella pneumoniae: investigating mortality and the impact of screening for KPC-2 with polymerase chain reaction. J Hosp Infect. 2015; 89: 179-185. doi: 10.1016/j.jhin.2014.11.012

35. Martins, I. S., Moreira, B. M., Riley, L. W., and Santoro-Lopes, G. Outbreak of extendedspectrum beta-lactamase producing Klebsiella pneumoniae infection among renal transplant recipients. J Hosp Infect. 2006; 64: 305-308. doi: 10.1016/j.jhin.2006.07.011

36. Huang, S. S., Yokoe, D. S., Hinrichsen, V. L., et al. Impact of routine intensive care unit surveillance cultures and resultant barrier precautions on hospital-wide methicillinresistant Staphylococcus aureus bacteremia. Clin Infect Dis. 2006; 43: 971-978. doi: 10. 1086/507636 PMID: 16983607 